\title{
No association between polymorphisms in PTEN and primary ovarian insufficiency in a Han Chinese population
}

Weiwei Zou ${ }^{1,2,3}$, Binbin Wang ${ }^{4,5}$, Jing Wang ${ }^{4,5}$, Zhiguo Zhang ${ }^{1,2,3}$, Xiaofeng $X^{1,2,3}$, Beili Chen ${ }^{1,2,3}, X M^{4,5,6^{*}}$ and Yunxia Cao ${ }^{1,2,3^{*}}$

\begin{abstract}
Background: The aim of our study was to investigate the possible relationship between polymorphisms in PTEN (the phosphatase and tensin homolog located on chromosome ten in humans) and POI (primary ovarian insufficiency) in Chinese women.

Methods: Seven tag SNPs (single nucleotide polymorphisms) - rs1234219, rs1903858, rs2299939, rs35352882, rs17107001, rs2299941 and rs12572106 - were chosen from the CHB (Han Chinese people in Beijing, China) HapMap database. MALDI-TOF-MS (matrix-assisted laser desorption/ionisation time-of-flight mass spectrometry) was used to detect the genotype distribution of the seven SNPs among $148 \mathrm{POI}$ patients and 230 controls.

Results: No statistically significant difference was found in an association analysis of the seven SNPs in the allele frequencies, genotype frequencies, or haplotype distributions.

Conclusions: In summary, this study explored the relationship between polymorphisms in PTEN and POI in a Han Chinese population and suggests that polymorphisms in PTEN may not be associated with a risk of POI.
\end{abstract}

Keywords: Primary ovarian insufficiency, PTEN, Polymorphisms, Chinese Han population

\section{Background}

POI (primary ovarian insufficiency) is characterised by reduced ovarian function in women under 40 years of age. It results from a decrease in the number of ovarian follicles, follicle exhaustion or follicle insensitivity to gonadotropins [1]. It has been reported that approximately $1 \%$ of women under 40 years of age with a normal karyotype are affected by this disease [2]. In the vast majority of POI patients, its aetiology is unknown [3], but it is thought to have a genetic basis [2].

In mammals, the initial number of primordial follicles in the ovary is fixed early in life. Before puberty begins, partial primordial follicles in dormancy are activated and develop to the antral follicle stage. At the onset of puberty, antral follicles either develop into mature follicles

\footnotetext{
*Correspondence: NICGR@263.net; caoyunxia_profr@126.com

${ }^{4}$ Center for Genetics, National Research Institute for Family Planning, 12,

Dahuisi RoadHaidian, Beijing 100081, China

${ }^{1}$ Reproductive Medicine Center, Department of Obstetrics and Gynecology,

The First Affiliated Hospital of Anhui Medical University, Hefei, China

Full list of author information is available at the end of the article
}

or become apoptotic. The remaining primordial follicles remain in a dormant state and wait for further development or undergo apoptosis directly from dormancy [4]. The gradual and natural reduction and ultimate depletion in the number of primordial follicles leads to a gradual deterioration of the ovary, after which the female enters menopause [4]. How can primordial follicles maintain such a long dormant state during a female's entire reproductive life? Previous studies have found that some signal molecules, such as PTEN (the protein encoded by the phosphatase and tensin homolog located on chromosome ten in humans), are relevant to this process [5]. Deletion of Pten in mouse oocytes results in the premature activation and eventually exhaustion of the global primordial follicles in early adulthood and thus leads to premature ovarian insufficiency [5].

PTEN is a tumour suppressor that has dual-phosphatase activity. Down-regulation of its expression or dysfunction of the PTEN (the phosphatase and tensin homolog located on chromosome ten in humans) is closely related to the 
occurrence of numerous human tumours [6]. PTEN can influence cell apoptosis, invasion and angiogenesis through its down-regulation of the PI3K (phosphoinositide-3 kinase) signal pathway, and it can therefore inhibit the survival and invasion of tumour cells [6]. PTEN also plays an important role in stabilising chromosomes and participates in controlling DSB (DNA double-strand break) repair [7].

Mutations of Pten in ES (embryonic stem) cells have a negative influence on early embryonic differentiation in mice and lead to early embryonic death [8]. This suggests that Pten is essential for the development of mouse embryos [8]. Pten-knockout mice consistently exhibit higher levels of FSH and $\mathrm{LH}$, reduced ovarian function and female infertility [5]. Scientists have also cultured ovaries from newborn mice in vitro in the presence of a PTEN inhibitor and PI3K activator and found that primordial follicles were activated from dormancy [9]. They subsequently cultured human ovarian cortical fragments with the PTEN inhibitor; primordial follicles were activated and demonstrated the ability to develop into mature follicles [9].

Given the above findings, we suspected that functional deficiency or dysfunction of PTEN in humans might result in damaged ovarian functions and lead to primary ovarian insufficiency. We therefore explored a possible relationship between polymorphisms of PTEN and POI in Chinese women.

\section{Methods}

This study was approved by the institutional ethical committee of Anhui Medical University. All participants were informed of and consented to the experiment.

\section{Subjects}

In total, 378 Chinese women, including 148 POI patients (mean age \pm SD, $29.7 \pm 6.1$ years) (E2 $96.1 \pm 82.1 \mathrm{pmol} / \mathrm{L}$, FSH $74.1 \pm 30.6 \mathrm{mIU} / \mathrm{mL}, \mathrm{LH} 37.6 \pm 19.3 \mathrm{mIU} / \mathrm{mL})$ and 230 controls (mean age \pm SD, $30.2 \pm 3.7$ years) (E2 187.3 $\pm 92.5 \mathrm{pmol} / \mathrm{L}, \quad$ FSH $6.5 \pm 1.6 \mathrm{mIU} / \mathrm{mL}, \quad$ LH $5.3 \pm 3.1$ $\mathrm{mIU} / \mathrm{mL}$ ), were recruited from the First Affiliated Hospital, Anhui Medical University, China. We chose POI patients who had had amenorrhea for more than 6 months and had normal diploid karyotypes and serum FSH levels $>30 \mathrm{IU} / \mathrm{L}$ [10]. We excluded patients who had undergone pelvic surgery, had been diagnosed with an autoimmune disease, or had ever received chemotherapy or radiotherapy. All of the controls were healthy Chinese women with natural menstrual cycles, normal FSH values and no evidence of diseases affecting normal ovarian function (including large ovarian or ovarian endometriosis cysts, severe tubal lesions, hypothalamus or pituitary tumours, obesity, abnormal adrenal function, thyroid disease, etc.). The approval and consent of the institutional ethics committee of Anhui Medical University was obtained for this experiment.

Considering the pathogenic mechanism of PTEN, the POI patients were divided into several groups: those with primary amenorrhea and secondary amenorrhea and early amenorrhea (including 22 primary amenorrhea patients and 4 patients with amenorrhea that only experienced menarche, but developed amenorrhea immediately after the initial menses) and late amenorrhea (secondary amenorrhea, excluding 4 patients with amenorrhea that only experienced menarche, but developed amenorrhea immediately after the initial menses).

\section{Methods and genetic analysis}

A QIAamp DNA Blood Mini Kit (Qiagen, Germany) was used for genomic DNA purification from peripheral blood. Seven tag SNPs - rs1234219, rs1903858, rs2299939, rs35352882, rs17107001, rs2299941 and rs12572106 - were chosen from the CHB (Han Chinese people in Beijing, China) HapMap database [11]. The criteria for selection were tag SNPs with a MAF (minor allele frequency) $>0.05$ and $r^{2}>0.8$. MALDI-TOF-MS (matrix-assisted laser desorption/ionisation time-offlight mass spectrometry) (Illumina, US) was used to detect the genotypes of the seven SNPs in the extracted samples from the POI patients and controls. To control the quality, we performed the detections repeatedly in both standard samples and experimental samples.

\section{Statistical analysis}

Comparative analyses of the allele frequencies and genotype frequencies of rs1234219, rs1903858, rs2299939, rs35352882, rs17107001, rs2299941 and rs12572106 between POI patients and controls were performed with Pearson's chi-squared tests using SPSS 13.0 software. We used Fisher's exact test if the expected count was less than 5 in any of the cells. Odds ratios (ORs) and their matching $95 \%$ confidence intervals (CIs) were computed using logistic regression analysis via SPSS 13.0 software. The HWE (Hardy-Weinberg equilibrium) of each SNP polymorphism in POI patients and controls was evaluated using Pearson's chi-squared tests, and we also applied Fisher's exact test if the expected count was less than 5 in any of the cells. LD (Linkage disequilibrium), haplotype association analysis and permutation tests were performed using HaploView 4.2 software. Haplotypes with frequencies less than 0.05 were excluded. To avoid statistical errors, we performed multiple comparisons using Bonferroni correction. Data with pvalues $<0.05$ were considered statistically significant.

\section{Results}

The LD plot of the seven SNPs (single nucleotide polymorphisms) in the PTEN region is shown in Fig. 1. Only 
two SNPs (rs12572106 and rs2299941) were in strong LD. The seven SNPs are located in the introns of PTEN.

The allele frequencies and association analysis of the seven SNPs are shown in Table 1. In both POI patients and controls, the seven SNPs of PTEN were all in an HWE state. The allele frequencies of rs2299939 showed a statistically significant difference $(p<0.05)$ between POI patients and controls. However, after Bonferroni correction, no significant difference was found for any of the SNPs.

The genotype frequencies of the seven SNPs are shown in Table 2. There was no statistically significant difference for any of the SNPs between POI patients and controls in genotype frequencies.

The haplotype distributions of five SNPs are shown in Table 3. Only two genotypes were found for two SNPs (rs35352882 and rs17107001), and the MAF was under 0.05. Because the inclusion of those two SNPs could result in a considerable statistical error, we analysed only the other five SNPs for haplotype distributions. The $\mathrm{p}$-value of T-T-A-A-T showed a statistically significant difference $(p<0.05)$, but there was no significant difference after $10^{4}$ permutation tests.
There was no statistically significant difference in the allelic and genotypic distributions between primary and secondary amenorrhea, early and late amenorrhea and the control groups after Bonferroni correction (Table 4, Table 5).

\section{Discussion}

There are two mechanisms that are involved in the occurrence of POI: follicle dysfunction and follicle premature exhaustion [3]. Follicle premature exhaustion indicates the accelerated apoptosis of primordial follicles or premature activation of primordial follicles. Therefore, the survival of primordial follicles is necessary for normal ovarian function. Early researchers inferred that there are inhibitory factors in intact ovarian tissue that maintain the majority of primordial follicles in a dormant state [12]. Previous studies have demonstrated that the PI3K signal pathway is one of the crucial molecular mechanisms that are involved in the survival, dormancy and apoptosis of mammalian primordial follicles [13]. Multiple signal molecules of this pathway were recognised as either stimulating factors (such as Ribosomal protein S6) or inhibitory factors (such as tuberous sclerosis complex 1 and tuberous sclerosis complex 2) in

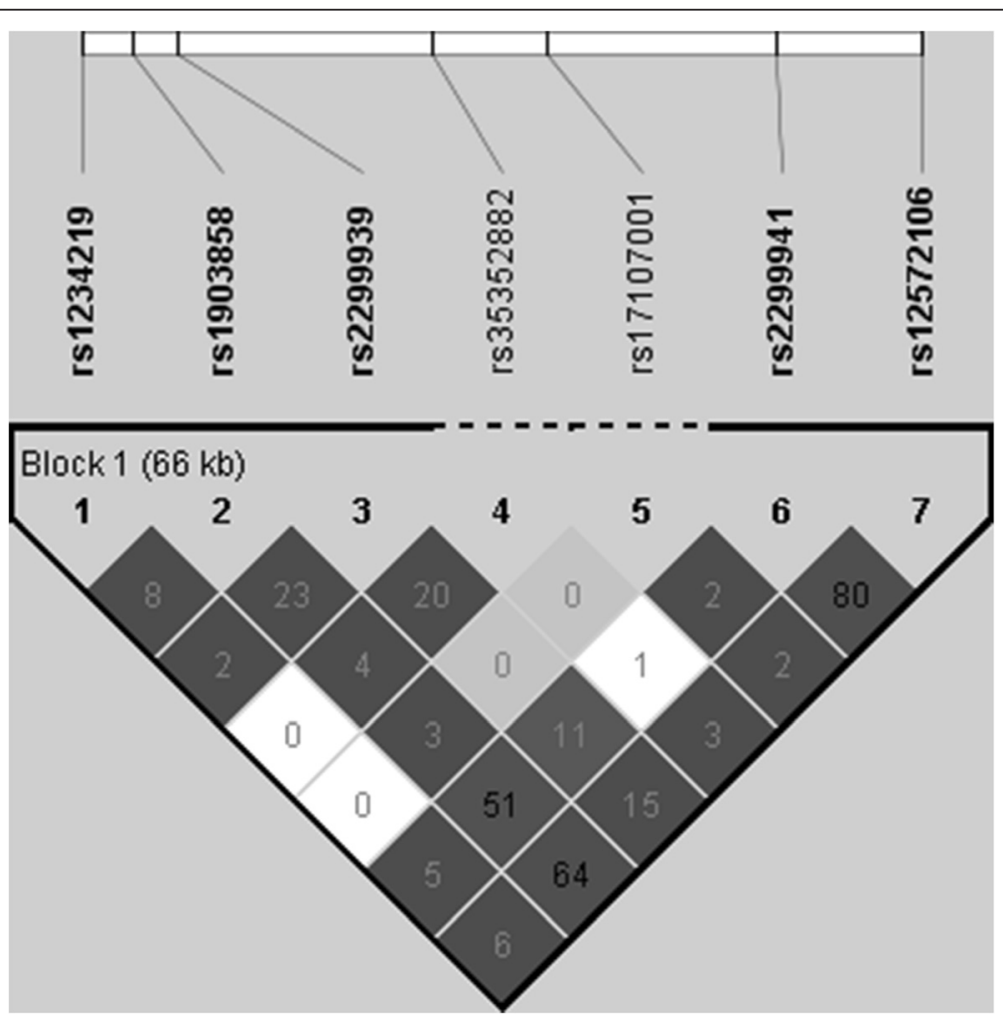

Fig. 1 Linkage disequilibrium LD plot of the seven SNPs (rs1234219, rs1903858, rs2299939, rs35352882, rs17107001, rs2299941 and rs12572106) in the PTEN region are shown. Calculation of the $r^{2}$ values, shown in each square, was based on data from 230 controls using HaploView 4.2 software. While two of the SNPs (rs12572106 and rs2299941) show a high LD, the other SNPs show a low LD $\left(r^{2}<0.8\right)$. rs35352882 and rs17107001 were excluded from the haplotype analyses and are therefore connected by a dotted line 
Table 1 The allele frequencies of the seven SNPs in PTEN between POI patients and controls

\begin{tabular}{|c|c|c|c|c|c|c|c|c|c|c|c|}
\hline SNP & Alleles & $\begin{array}{l}\text { Associated } \\
\text { allele }\end{array}$ & HWE cases & $\begin{array}{l}\text { HWE } \\
\text { controls }\end{array}$ & $\begin{array}{l}\text { MAF cases } \\
(n=148)\end{array}$ & $\begin{array}{l}\text { MAF controls } \\
(n=230)\end{array}$ & OR & $95 \% \mathrm{Cl}$ & Value & $p$ & $\begin{array}{l}\text { Bonferroni } \\
\text { correction }\end{array}$ \\
\hline rs1234219 & $\mathrm{T} / \mathrm{C}$ & $C$ & 0.95 & 0.72 & 0.084 & 0.084 & 1.010 & $0.596-1.711$ & 0.001 & 0.971 & 1.000 \\
\hline rs1903858 & $\mathrm{C} / \mathrm{T}$ & C & 0.60 & 0.90 & 0.446 & 0.509 & 0.777 & $0.579-1.043$ & 2.834 & 0.092 & 0.644 \\
\hline rs2299939 & $C / A$ & C & 0.45 & 0.16 & 0.146 & 0.206 & 0.661 & $0.445-0.982$ & 4.230 & 0.040 & 0.280 \\
\hline rs35352882 & $\mathrm{T} / \mathrm{C}$ & C & 0.58 & 0.51 & 0.044 & 0.042 & 1.047 & $0.509-2.153$ & 0.015 & 0.901 & 1.000 \\
\hline rs17107001 & $\mathrm{G} / \mathrm{T}$ & $\mathrm{T}$ & 0.64 & 0.63 & 0.037 & 0.031 & 1.208 & $0.541-2.697$ & 0.212 & 0.645 & 1.000 \\
\hline rs2299941 & $A / G$ & G & 0.68 & 0.62 & 0.378 & 0.354 & 1.111 & $0.820-1.505$ & 0.460 & 0.498 & 1.000 \\
\hline rs12572106 & $T / C$ & C & 0.74 & 0.44 & 0.443 & 0.389 & 1.245 & $0.925-1.676$ & 2.091 & 0.148 & 1.000 \\
\hline
\end{tabular}

The allele frequencies were performed with Pearson's chi-squared test or Fisher's exact test using SPSS 13.0 software. The allele frequencies of rs2299939 showed no significant difference after Bonferroni correction between POI patients and the controls

maintaining the balance of the activation and dormancy of mammalian primordial follicles [13, 14]. PTEN downregulates the PI3K signal pathway [13]. The functional deficiency or dysfunction of Pten leads to continuous and excessive activation of the downstream signal pathway and results in excessive activation and depletion of primordial follicles, ultimately leading to ovarian failure in mice $[13,14]$. Before the complete depletion of primordial follicles, Pten mutant mice undergo normal ovulation and generate normal offspring $[15,16]$.

In the present study, we sought to study the relationship between seven SNPs (rs1234219, rs1903858, rs2299939, rs35352882, rs17107001, rs2299941 and rs12572106) in PTEN and POI in 148 POI patients and 230 controls. We performed an association analysis of the seven SNPs with regard to their allele frequencies, genotype

Table 2 The genotype frequencies of the seven SNPS in PTEN between POI patients and controls

\begin{tabular}{|c|c|c|c|c|c|c|c|}
\hline \multirow{2}{*}{$\frac{\text { SNP }}{\text { rs1234219 }}$} & \multicolumn{4}{|c|}{ Genotypes, n } & \multirow[t]{2}{*}{ Value } & \multirow[t]{2}{*}{$\mathrm{p}$} & \multirow[t]{2}{*}{ OR $(95 \% \mathrm{Cl})$} \\
\hline & $T / T$ & $\mathrm{~T} / \mathrm{C}$ & $C / C$ & Missing & & & \\
\hline Cases & 124 & 23 & 1 & 0 & 0.201 & 0.950 & $0.770(0.069-8.584)$ \\
\hline Controls & 191 & 34 & 2 & 3 & & & $1.042(0.586-1.852)$ \\
\hline rs1903858 & $\mathrm{C} / \mathrm{C}$ & $C / T$ & $\mathrm{~T} / \mathrm{T}$ & Missing & & & \\
\hline Cases & 47 & 70 & 31 & 0 & 2.889 & 0.236 & $1.367(0.837-2.233)$ \\
\hline Controls & 55 & 112 & 59 & 4 & & & $0.841(0.496-1.425)$ \\
\hline rs2299939 & $\mathrm{C} / \mathrm{C}$ & $\mathrm{C} / \mathrm{A}$ & $\mathrm{A} / \mathrm{A}$ & Missing & & & \\
\hline Cases & 106 & 39 & 2 & 1 & 5.319 & 0.070 & $4.719(1.043-21.353)$ \\
\hline Controls & 146 & 67 & 13 & 4 & & & $3.784(0.811-17.651)$ \\
\hline rs35352882 & $\mathrm{T} / \mathrm{T}$ & $\mathrm{T} / \mathrm{C}$ & $\mathrm{C} / \mathrm{C}$ & Missing & & & \\
\hline Cases & 135 & 13 & 0 & 0 & 0.016 & 0.899 & $1.049(0.502-2.195)$ \\
\hline Controls & 207 & 19 & 0 & 4 & & & \\
\hline rs17107001 & $\mathrm{G} / \mathrm{G}$ & $\mathrm{G} / \mathrm{T}$ & $\mathrm{T} / \mathrm{T}$ & Missing & & & \\
\hline Cases & 137 & 11 & 0 & 0 & 0.220 & 0.639 & $0.822(0.363-1.864)$ \\
\hline Controls & 212 & 14 & 0 & 4 & & & \\
\hline rs2299941 & A/A & $A / G$ & $\mathrm{G} / \mathrm{G}$ & Missing & & & \\
\hline Cases & 56 & 72 & 20 & 0 & 0.854 & 0.652 & $1.080(0.568-2.052)$ \\
\hline Controls & 96 & 100 & 30 & 4 & & & $0.875(0.455-1.684)$ \\
\hline rs12572106 & T/T/ & $\mathrm{T} / \mathrm{C}$ & $\mathrm{C} / \mathrm{C}$ & Missing & & & \\
\hline Cases & 47 & 71 & 30 & 0 & 2.048 & 0.359 & $1.501(0.825-2.730)$ \\
\hline Controls & 87 & 102 & 37 & 4 & & & $1.288(0.808-2.054)$ \\
\hline
\end{tabular}


Table 3 The haplotype distributions of PTEN polymorphisms in POI patients and controls

\begin{tabular}{lccccc}
\hline Haplotype & Total frequency & Cases frequency & Controls frequency & $p$-value & $p$-value from permutation \\
\hline T-C-C-G-C & 0.358 & 0.378 & 0.345 & 0.355 & 0.820 \\
T-T-C-A-T & 0.302 & 0.301 & 0.302 & 0.959 & 1.000 \\
T-T-A-A-T & 0.181 & 0.145 & 0.204 & 0.042 & 0.175 \\
C-C-C-A-T & 0.084 & 0.084 & 0.084 & 0.971 & 1.000 \\
\hline
\end{tabular}

The haplotype association analysis was performed using the HaploView 4.2 software. The p-value of T-T-A-A-T showed a statistically significant difference, but there was no significant difference after $10^{4}$ permutation tests

frequencies and haplotype distributions. Rs2299939 showed a statistically significant difference in allele frequency, but the difference disappeared after Bonferroni correction. Haplotype T-T-A-A-T showed an association with POI, but it too disappeared after $10^{4}$ permutation tests.
POI is a complex disease that involves multiple genes. Although many genes have been confirmed as being involved in the development of POI [2], the cause of most cases remains unidentified. Therefore, many investigators have devoted their research to identifying the

Table 4 The association analysis of the seven SNPs among the primary amenorrhea, secondary amenorrhea and control groups

\begin{tabular}{|c|c|c|c|c|c|c|c|c|c|c|c|}
\hline \multirow{2}{*}{$\frac{S N P}{\text { Ss1234219 }}$} & \multicolumn{4}{|c|}{ Genotypes, n } & \multirow[t]{2}{*}{ Value } & \multirow[t]{2}{*}{$p$} & \multicolumn{2}{|c|}{ Alleles } & \multirow[t]{2}{*}{ Value } & \multirow[t]{2}{*}{$P$} & \multirow[t]{2}{*}{ Bonferroni correction } \\
\hline & $\mathrm{T} / \mathrm{T}$ & $\mathrm{T} / \mathrm{C}$ & $\mathrm{C} / \mathrm{C}$ & Missing & & & $T$ & C & & & \\
\hline Primary amenorrhea & 19 & 3 & 0 & 0 & 0.659 & 0.989 & 41 & 3 & 0.093 & 0.976 & 1.000 \\
\hline Secondary amenorrhea & 105 & 20 & 1 & 0 & & & 230 & 22 & & & \\
\hline Controls & 191 & 34 & 2 & 3 & & & 416 & 38 & & & \\
\hline rs1903858 & $\mathrm{C} / \mathrm{C}$ & $\mathrm{C} / \mathrm{T}$ & $\mathrm{T} / \mathrm{T}$ & Missing & & & C & $\mathrm{T}$ & & & \\
\hline Primary amenorrhea & 3 & 14 & 5 & 0 & 7.452 & 0.114 & 20 & 24 & 4.883 & 0.087 & 0.609 \\
\hline Secondary amenorrhea & 44 & 56 & 26 & 0 & & & 144 & 108 & & & \\
\hline Controls & 55 & 112 & 59 & 4 & & & 222 & 230 & & & \\
\hline rs2299939 & $\mathrm{C} / \mathrm{C}$ & $C / A$ & $\mathrm{~A} / \mathrm{A}$ & Missing & & & C & A & & & \\
\hline Primary amenorrhea & 19 & 3 & 0 & 0 & 6.694 & 0.132 & 41 & 3 & 6.346 & 0.042 & 0.294 \\
\hline Secondary amenorrhea & 87 & 36 & 2 & 1 & & & 210 & 40 & & & \\
\hline Controls & 146 & 67 & 13 & 4 & & & 359 & 93 & & & \\
\hline rs35352882 & $\mathrm{T} / \mathrm{T}$ & $\mathrm{T} / \mathrm{C}$ & $\mathrm{C} / \mathrm{C}$ & Missing & & & $\mathrm{T}$ & C & & & \\
\hline Primary amenorrhea & 20 & 2 & 0 & 0 & 0.179 & 1.000 & 42 & 2 & 0.180 & 0.956 & 1.000 \\
\hline Secondary amenorrhea & 115 & 11 & 0 & 0 & & & 241 & 11 & & & \\
\hline Controls & 207 & 19 & 0 & 4 & & & 433 & 19 & & & \\
\hline rs17107001 & $\mathrm{G} / \mathrm{G}$ & $\mathrm{G} / \mathrm{T}$ & $\mathrm{T} / \mathrm{T}$ & Missing & & & G & $\mathrm{T}$ & & & \\
\hline Primary amenorrhea & 21 & 1 & 0 & 0 & 0.478 & 0.832 & 43 & 1 & 0.451 & 0.835 & 1.000 \\
\hline Secondary amenorrhea & 116 & 10 & 0 & 0 & & & 242 & 10 & & & \\
\hline Controls & 212 & 14 & 0 & 4 & & & 438 & 14 & & & \\
\hline rs2299941 & A/A & $A / G$ & $\mathrm{G} / \mathrm{G}$ & Missing & & & A & G & & & \\
\hline Primary amenorrhea & 9 & 11 & 2 & 0 & 1.205 & 0.886 & 29 & 15 & 0.774 & 0.679 & 1.000 \\
\hline Secondary amenorrhea & 47 & 61 & 18 & 0 & & & 155 & 97 & & & \\
\hline Controls & 96 & 100 & 30 & 4 & & & 292 & 160 & & & \\
\hline rs12572106 & $\mathrm{T} / \mathrm{T}$ & $\mathrm{T} / \mathrm{C}$ & $\mathrm{C} / \mathrm{C}$ & Missing & & & $\mathrm{T}$ & C & & & \\
\hline Primary amenorrhea & 7 & 13 & 2 & 0 & 4.244 & 0.370 & 27 & 17 & 2.766 & 0.251 & 1.000 \\
\hline Secondary amenorrhea & 40 & 58 & 28 & 0 & & & 138 & 114 & & & \\
\hline Controls & 87 & 102 & 37 & 4 & & & 276 & 176 & & & \\
\hline
\end{tabular}

The allele and genotype frequencies among the primary amenorrhea, secondary amenorrhea and control groups were performed with Pearson's chi-squared test or Fisher's exact test using SPSS 13.0 software. There was no statistically significant difference in the allelic and genotypic distributions between the primary amenorrhea, secondary amenorrhea and control groups after Bonferroni correction 
Table 5 The association analysis of the seven SNPs among the early amenorrhea, late amenorrhea and control groups

\begin{tabular}{|c|c|c|c|c|c|c|c|c|c|c|c|}
\hline \multirow{2}{*}{$\frac{\text { SNP }}{\text { rs1234219 }}$} & \multicolumn{4}{|c|}{ Genotype, n (\%) } & \multirow[t]{2}{*}{ Value } & \multirow{2}{*}{$\frac{p}{0.945}$} & \multicolumn{2}{|c|}{ Alleles } & \multirow[t]{2}{*}{ Value } & \multirow{2}{*}{$\frac{P}{0.810}$} & \multirow{2}{*}{$\begin{array}{l}\text { Bonferroni correction } \\
1.000\end{array}$} \\
\hline & $T / T$ & T/C & $\mathrm{C} / \mathrm{C}$ & Missing & & & $\mathrm{T}$ & C & & & \\
\hline Early amenorrhea & 23 & 3 & 0 & 0 & 0.820 & & 49 & 3 & 0.418 & & \\
\hline Late amenorrhea & 101 & 20 & 1 & 0 & & & 222 & 22 & & & \\
\hline Controls & 191 & 34 & 2 & 3 & & & 416 & 38 & & & \\
\hline rs1903858 & $\mathrm{C} / \mathrm{C}$ & $C / T$ & $\mathrm{~T} / \mathrm{T}$ & Missing & & 0.195 & C & $\mathrm{T}$ & & 0.168 & 1.000 \\
\hline Early amenorrhea & 5 & 16 & 5 & 0 & 6.057 & & 26 & 26 & 3.572 & & \\
\hline Late amenorrhea & 42 & 54 & 26 & 0 & & & 138 & 106 & & & \\
\hline Controls & 55 & 112 & 59 & 4 & & & 222 & 230 & & & \\
\hline rs2299939 & $\mathrm{C} / \mathrm{C}$ & C/A & $\mathrm{A} / \mathrm{A}$ & Missing & & 0.143 & $C$ & A & & 0.044 & 0.308 \\
\hline Early amenorrhea & 22 & 4 & 0 & 0 & 6.515 & & 48 & 4 & 6.267 & & \\
\hline Late amenorrhea & 84 & 35 & 2 & 1 & & & 203 & 39 & & & \\
\hline Controls & 146 & 67 & 13 & 4 & & & 359 & 93 & & & \\
\hline rs35352882 & $\mathrm{T} / \mathrm{T}$ & T/C & $\mathrm{C} / \mathrm{C}$ & Missing & & 0.955 & T & $C$ & & 0.957 & 1.000 \\
\hline Early amenorrhea & 24 & 2 & 0 & 0 & 0.101 & & 50 & 2 & 0.095 & & \\
\hline Late amenorrhea & 111 & 11 & 0 & 0 & & & 233 & 11 & & & \\
\hline Controls & 207 & 19 & 0 & 4 & & & 433 & 19 & & & \\
\hline rs17107001 & $\mathrm{G} / \mathrm{G}$ & $\mathrm{G} / \mathrm{T}$ & $\mathrm{T} / \mathrm{T}$ & Missing & & 0.704 & G & $\mathrm{T}$ & & 0.711 & 1.000 \\
\hline Early amenorrhea & 25 & 1 & 0 & 0 & 0.679 & & 51 & 1 & 0.840 & & \\
\hline Late amenorrhea & 112 & 10 & 0 & 0 & & & 234 & 10 & & & \\
\hline Controls & 212 & 14 & 0 & 4 & & & 438 & 14 & & & \\
\hline rs2299941 & $\mathrm{A} / \mathrm{A}$ & $A / G$ & $\mathrm{G} / \mathrm{G}$ & Missing & & 0.731 & A & G & & 0.776 & 1.000 \\
\hline Early amenorrhea & 9 & 15 & 2 & 0 & 2.056 & & 33 & 19 & 0.506 & & \\
\hline Late amenorrhea & 47 & 57 & 18 & 0 & & & 151 & 93 & & & \\
\hline Controls & 96 & 100 & 30 & 4 & & & 292 & 160 & & & \\
\hline rs12572106 & $\mathrm{T} / \mathrm{T}$ & T/C & $\mathrm{C} / \mathrm{C}$ & Missing & & 0.527 & T & C & & 0.352 & 1.000 \\
\hline Early amenorrhea & 7 & 15 & 4 & 0 & 3.189 & & 29 & 23 & 2.091 & & \\
\hline Late amenorrhea & 40 & 56 & 26 & 0 & & & 136 & 108 & & & \\
\hline Controls & 87 & 102 & 37 & 4 & & & 276 & 176 & & & \\
\hline
\end{tabular}

The allele and genotype frequencies among the early amenorrhea, late amenorrhea and control groups were performed with Pearson's chi-squared test or Fisher's exact test using SPSS 13.0 software. There was no statistically significant difference in the allelic and genotypic distributions between the early amenorrhea, late amenorrhea and control groups after Bonferroni correction

aetiology of POI. Because previous studies have found that the deletion of PTEN in oocytes leads to the failure of ovarian function in mice [5], we sought to determine whether PTEN is involved in the incidence and development of human POI. We did not find an association between POI and any risk alleles, genotypes or haplotypes. There are several possible explanations for these results. First, PTEN has never been demonstrated to be associated with human POI. In addition, specific differences between mice and humans may account for genetic differences in the PTEN region. Although researchers have found that compared to mice more primordial follicles were activated in human ovarian cortical fragments after treatment with a PTEN inhibitor [9], they did not analyse the statistical significance of the difference. In addition, that study's sample size may not have been sufficiently large. In the previous study, the increased gonadotropin concentrations, morphological changes of the ovary and the depletion of primordial follicles began to appear 12 weeks postnatal in PTEN mutant mice. In humans, the period from birth to puberty may last over 10 years. If the gene mutation or abnormal function of PTEN occurs in the embryonic or early life, it is likely that ovarian primordial follicles may be activated and exhausted before puberty, which may present as primary amenorrhea. If the gene mutation or abnormal function of PTEN occurs after puberty, it behaves as secondary amenorrhea. Therefore, we divided the cases into primary and secondary amenorrhea and early and late amenorrhea and compared the patients with the controls. If we obtained 
meaningful results, we could affirm the association between PTEN and POI and could also infer the approximate time of the PTEN mutation. Rs2299939 showed a statistically significant difference between these groups in allele frequency, but the difference disappeared after Bonferroni correction. The primary amenorrhea sample size was too small. A larger sample size of primary amenorrhea POI patients may yield statistically significant results, especially considering the promising rs2299939 allele and T-T-A-A-T haplotype.

Researchers analysed the PCR products of the PTEN encoding region via direct sequencing in 20 idiopathic POI patients and 20 controls, but found no meaningful mutation [17]. We hypothesise that a larger sample size may improve results, and in population genetics, many different results are due to the varied composition of the studied populations. Chinese scientists had already performed a mutation analysis of nine exons of PTEN in 161 Chinese women with POI but did not observe any mutations or variants [18]. The sample size of their study was similar to the sample size used in the present study, and they researched PTEN from various angles, performing mutational analysis of exons and conducting an association study of intronic SNPs. The two studies mutually remedy their respective defects and together indicate that PTEN may not participate in the pathogenesis of POI. In addition, the POI patients in the two studies were all secondary amenorrhea patients. Thus, we need to confirm the results in a larger sample of patients with primary amenorrhea.

\section{Conclusions}

In summary, this study investigated the relationship between polymorphisms of PTEN and POI in a Chinese Han population. Our findings suggest that PTEN may not be a common pathogenic gene for POI in humans. However, further studies in a larger sample size or functional studies of PTEN are needed to verify these results.

\begin{abstract}
Abbreviations
CHB: (Han Chinese people in Beijing, China); Cl: (confidence interval); DSB: (DNA double-strand break); ES: (Embryonic stem); HWE: (Hardy-Weinberg equilibrium); LD: (Linkage disequilibrium); MALDI-TOF-MS: (Matrix-assisted laser desorption/ionisation time-of-flight mass spectrometry); OR: (Odds ratio); PI3K: (Phosphoinositide-3 kinase); POI: (primary ovarian insufficiency); PTEN: (the phosphatase and tensin homolog located on chromosome ten in humans); PTEN: (The protein encoded by the phosphatase and tensin homolog located on chromosome ten in humans); SNP: (Single nucleotide polymorphism).
\end{abstract}

\section{Competing interests}

The authors declare that they have no competing interests.

\section{Authors' contributions}

WZ completed the molecular genetic studies and drafted the manuscript. BW participated in the design of the study and performed the statistical analysis. JW performed the statistical analysis. ZZ, XX and BC participated in the acquisition of samples. XM participated in the design of the study and helped to draft the manuscript. YC conceived of the study, participated in its design and helped to draft the manuscript. All of the authors read and approved the final manuscript.

\section{Acknowledgments}

The authors thank all of the women who participated in this study and all of the clinicians who collected these cases. We thank Yunxia Cao, who provided medical writing services on behalf of the State Key Development Program for Basic Research of China (2012CB944704) and the National Natural Science Foundation of China (30973197). We thank the English language professional service (http://webshop.elsevier.com/languageediting/) for correcting the spelling and grammar errors. This study was supported by the State Key Development Program for Basic Research of China (2012CB944704) and the National Natural Science Foundation of China (30973197).

\section{Author details}

${ }^{1}$ Reproductive Medicine Center, Department of Obstetrics and Gynecology, The First Affiliated Hospital of Anhui Medical University, Hefei, China. ${ }^{2}$ Institute of Reproductive Genetics, Anhui Medical University, Hefei, China. ${ }^{3}$ Anhui Provincial Engineering Technology Research Center for Biopreservation and Artificial Organs, Hefei, China. ${ }^{4}$ Center for Genetics, National Research Institute for Family Planning, 12, Dahuisi RoadHaidian, Beijing 100081, China. ${ }^{5}$ Peking Union Medical College, Beijing, China. ${ }^{6}$ World Health Organization Collaborating Centre for Research in Human Reproduction, Beijing, China.

Received: 26 January 2015 Accepted: 1 June 2015

Published online: 17 June 2015

\section{References}

1. Welt CK. Primary ovarian insufficiency: a more accurate term for premature ovarian failure. Clin Endocrinol (Oxf). 2008;68:499-509.

2. Cordts EB, Christofolini DM, Dos Santos AA, Bianco B, Barbosa CP. Genetic aspects of premature ovarian failure: a literature review. Arch Gynecol Obstet. 2011;283:635-43.

3. Nelson LM. Clinical practice. Primary ovarian insufficiency. N Engl J Med. 2011;360:606-14

4. McGee EA, Hsueh AJ. Initial and cyclic recruitment of ovarian follicles. Endocr Rev. 2000;21:200-14.

5. Reddy P, Liu L, Adhikari D, Jagarlamudi K, Rajareddy S, Shen Y, et al. Oocyte-specific deletion of Pten causes premature activation of the primordial follicle pool. Science. 2000;319:611-3.

6. Jiang BH, Liu LZ. PI3K/PTEN signaling in angiogenesis and tumorigenesis. Adv Cancer Res. 2009;102:19-65.

7. Shen WH, Balajee AS, Wang J, Wu H, Eng C, Pandolfi PP, et al. Essential role for nuclear PTEN in maintaining chromosomal integrity. Cell. 2007;128:157-70.

8. Di Cristofano A, Pesce B, Cordon-Cardo C, Pandolfi PP. Pten is essential for embryonic development and tumour suppression. Nat Genet. 2007:19:348-55.

9. Li J, Kawamura K, Cheng Y, Liu S, Klein C, Liu S, et al. Activation of dormant ovarian follicles to generate mature eggs. Proc Natl Acad Sci U S A. 2010;107:10280-4.

10. Beck-Peccoz P, Persani L. Premature ovarian failure. Orphanet J Rare Dis. 2006;1:9.

11. The HapMap database. http://www.hapmap.org.

12. Wandji SA, Srsen V, Voss AK, Eppig JJ, Fortune JE. Initiation in vitro of growth of bovine primordial follicles. Biol Reprod. 1996;55:942-8.

13. Reddy P, Zheng W, Liu K. Mechanisms maintaining the dormancy and survival of mammalian primordial follicles. Trends Endocrinol Metab. 2010;21:96-103.

14. Adhikari D, Liu K. Molecular mechanisms underlying the activation of mammalian primordial follicles. Endocr Rev. 2009;30:438-64.

15. John GB, Gallardo TD, Shirley L, Castrillon DH. Foxo3 is a PI3K-dependent molecular switch controlling the initiation of oocyte growth. Dev Biol. 2008;321:197-204.

16. Jagarlamudi K, Liu L, Adhikari D, Reddy P, Idahl A, Ottander U, et al. Oocyte-specific deletion of Pten in mice reveals a stage-specific function of PTEN/PI3K signaling in oocytes in controlling follicular activation. PLoS One. 2009;::e6186. 
17. Shimizu Y, Kimura F, Takebayashi K, Fujiwara M, Takakura K, Takahashi K. Mutational analysis of the PTEN gene in women with premature ovarian failure. Acta Obstet Gynecol Scand. 2009;88:824-5.

18. Zhao Z, Qin Y, Ma J, Zhao H, Li J, Wang L, et al. PTEN gene analysis in premature ovarian failure patients. Acta Obstet Gynecol Scand. 2011;90:678-9.

Submit your next manuscript to BioMed Central and take full advantage of:

- Convenient online submission

- Thorough peer review

- No space constraints or color figure charges

- Immediate publication on acceptance

- Inclusion in PubMed, CAS, Scopus and Google Scholar

- Research which is freely available for redistribution 